\title{
OUVINDO AS VOZES DOS PROFESSORES DA EDUCAÇÃO BÁSICA: O QUE QUEREMOS DE/COM FORMAÇÃO DOCENTE
}

\author{
Kauane Oliveira de Jesus ${ }^{1}$ \\ Ivonete Barreto de Amorim² \\ César Costa Vitorino ${ }^{3}$
}

\footnotetext{
1 Universidade do Estado da Bahia (UNEB) Campus XI, Serrinha, BA, Brasil.

${ }^{2}$ Universidade do Estado da Bahia (UNEB) Campus XI, Serrinha, BA, Brasil.

${ }^{3}$ Universidade do Estado da Bahia (UNEB) Campus XI, Serrinha, BA, Brasil.
}

Resumo: $O$ presente trabalho tem como finalidade analisar as demandas formativas dos/das docentes/pedagogos/as que atuam na Educação Básica. Os teóricos que balizaram este estudo foram: Nóvoa (2009), Carbonneau (2006), Gatti (2012), Larrosa (2002) Gatti (2011) e Santos (2018). A metodologia consistiu em uma pesquisa qualitativa, tendo como estratégia de coleta das informações entrevistas semiestruturadas com 3 (três) pedagogas graduadas pela Universidade do Estado da Bahia (UNEB), campus XI, atuantes na Educação Básica. Para melhor compreensão foram abordados enfoques sobre a formação docente, o papel do educador e os olhares das professoras colaboradoras da pesquisa. Através desta pesquisa foi possível elaborar um olhar mais intenso e crítico sobre a profissionalização dos educadores na atualidade e a necessidade de demandas formativas de pedagogas atuantes na educação básica.

Palavras-chave: Formação docente. Saberes docente. Demandas formativas. Pesquisa qualitativa. Território do sisal.

\begin{abstract}
This paper aims to analyze the formative demands of teachers / educators who work in Basic Education. The theorists that guided this study were: Nóvoa (2009), Carbonneau (2006), Gatti (2012), Larrosa (2002) Gatti (2011) and Santos (2018). The methodology consisted of a qualitative research, having as strategy of collecting information semi-structured interviews with 3 (three) pedagogues graduated by the State University of Bahia (UNEB), campus $\mathrm{Xl}$, acting in Basic Education. For better understanding were approached the teacher formation, the role of the educator and the eyes of the collaborating teachers of the research. Through this research it was possible to elaborate a more intense and critical look on the professionalization of educators today and the need for formative demands of pedagogues working in basic education.
\end{abstract}

Key-words: Teacher training. Teaching knowledge. Formative demands. Qualitative research. Sisal Territory.

Como citar: JESUS, K. O; AMORIM, I. B; VITORINO, C. C. Ouvindo as vozes dos professores da educação básica: o que queremos de/com formação docente. Revista Científica Novas Configurações - Diálogos Plurais, Luziânia, v. 1, n.1, p. 12-20, 2020. https://doi.org/.10.4322/2675-4177.2020.003

\section{INTRODUÇÃO}

Este estudo tem como intuito apresentar reflexões sobre as professoras egressas do Curso de Pedagogia da Universidade do Estado da Bahia (UNEB), Departamento de Educação campus XISerrinha-BA, que atuam na Educação Básica no Território do Sisal. A investigação está interligada com o

Apoio financeiro: Nenhum.

Conflitos de interesses: Os autores declaram não haver nenhum conflito de interesse.

Correspondência: ivoneteeducadora@hotmail.com

Recebido: 05 Mar 2020

Aprovado: 18 Mai 2020

Editor: Marcelo Máximo Purificação.

Este é um artigo publicado em acesso aberto (Open Access) sob a licença Creative Commons Attribution, que permite uso, distribuição e reprodução em qualquer meio, sem restrições desde que o trabalho original seja corretamente citado. 
Projeto de Pesquisa "Formação de professores da educação básica: demandas da/na práxis", vincada na Iniciação Científica.

Em tempo, é importante destacar que a formação precisa ser vista como um momento de reflexão crítica, pois os educadores têm a incumbência de analisar suas concepções pedagógicas, aprofundar seus saberes, rever suas metodologias, visão que incide em compreender que todos esses pontos são essenciais na sua carreia profissional e irão fazer parte da construção de sua identidade.

Nesta conjuntura, se instaura a seguinte questão de pesquisa: Quais demandas formativas dos/as docentes/pedagogos/as que atuam na educação básica do território sisal? Diante dessa inquietação, ouvir as vozes de egressos do curso de Pedagogia é condição fundante para desvelar as demandas que estes vivenciam na práxis.

Partindo desse pressuposto, este artigo ficou estruturado em quatro seções, a saber: a introdução; articulação entre formação docente e educação básica; metodologia, análise e discussão das informações e considerações finais.

\section{ARTICULAÇÃO ENTRE FORMAÇÃO DOCENTE E EDUCAÇÃO BÁSICA}

A história da educação brasileira é marcada por rupturas, a cada período histórico a educação passa por mudanças, essas transformações podem desencadear pontos negativos e positivos. Segundo Carbonneau (2006) os aspectos culturais, sociais, políticos e econômicos têm forte influência na educação, pois estes refletem no espaço educacional.

Neste viés Nóvoa (2009, p.28) afirma:

[...] Os anos 70 foram marcados pela racionalização do ensino, a pedagogia por objectivos, a planificação. Os anos 80 pelas reformas educativas e pela atenção às questões do currículo. Os anos 90 pela organização, administração e gestão dos estabelecimentos de ensino. Agora, parece ter voltado o tempo dos professores.

Diante do exposto, percebe-se que o histórico da educação é marcado por um processo complexo, o regime que era instituído elaborava um novo modelo educacional; a princípio, tentaram compreender o ensino apontando alternativas dentro da pedagogia, além disso, reconfiguraram o currículo, sendo que passaram a analisar o órgão gestor das instituições responsáveis pelo seu desenvolvimento.

No século XXI o campo estudado se refere à formação de professores, o qual é vista como uma área que precisa ser avaliada com mais rigor, passando a ter um olhar epistemológico diante das lacunas existentes, pois há diversos enunciados que divulgam esse assunto, desta forma acabam reproduzindo os mesmos conceitos sem haver uma busca pela mudança dentro desse campo amplo, considerado como uma etapa importante na vida de cada indivíduo.

Diversas inquietações surgiram diante do processo de formação docente, questionamentos que se manifestaram com base no crescente número das demandas presentes na sociedade, tendo como intuito compreender as políticas públicas que conduzem essa formação, os planos curriculares, a ligação da prática com a teoria, os fundamentos teóricos abordados, entre outros, todos esses aspectos são vistos como elementos que devem ser prezados no percurso formativo nos dias atuais.

Desta forma, o engajamento do corpo educacional, o desenvolvimento de uma gestão democrática e participativa, o diálogo entre os atores educativos, família e sociedade são de grande relevância para atender os problemas educacionais, além de proporcionar uma transformação significativa dentro da educação.

Nesta perspectiva, Nóvoa (2009) enfatiza que a formação docente é realizada no próprio local de trabalho, onde os professores irão partilhar experiências da docência, adquirir informações novas, rever seus conceitos e elaborar juntamente com os profissionais da educação ações eficazes para tornar este campo acessível, capaz de atender as necessidades e reconhecer a realidade de cada estudante inserido em um determinado contexto.

A explanação deste teórico apresenta que "a formação de professores deve estar marcada por um princípio de responsabilidade social, favorecendo a comunicação pública e a participação profissional no espaço público da educação" (NÓVOA, 2009, p.42). O ambiente escolar é, via de regra, propício para o professor lançar suas experiências adquiridas durante as formações, sem perder de vista a autoavaliação da própria prática. É verdade que os educadores desenvolvem uma função essencial dentro da área educacional, sendo assim a ação aplicada deve ser de qualidade e suas concepções necessitam centrar-se na aprendizagem dos educandos, criando possibilidades para que cada aluno seja o construtor do seu próprio conhecimento. 
Seguindo esta linha de pensamento, Nóvoa (2009) afirma que o trabalho realizado em conjunto é de suma importância para o desenvolvimento da área educacional, todos os membros da equipe escolar devem estar articulados na elaboração de ações necessárias ao progresso do ambiente educacional. Independente do meio político, social e cultural de um indivíduo, o professor é responsável em estimular o desenvolvimento do senso crítico, promovendo a formação cidadã, pois, a educação possibilita que o sujeito conquiste sua autonomia e lute pela garantia dos seus direitos e cumprimento dos seus deveres.

Na prática docente é necessário que os educadores conheçam seu local de trabalho, a gestão escolar que rege a instituição, o Projeto Político Pedagógico (PPP), para que possam intervir, construir propostas educativas e colocá-las em prática.

Segundo Gatti (2012) além da preocupação pela formação existem as diversidades presentes nas instituições escolares como: os transtornos globais, problemas familiares, carência no atendimento dos programas da escola (merendas, transportes, recursos didáticos) e as dificuldades de aprendizagens que desencadeiam na sala de aula e o professor precisa estar bem informado teoricamente para realizar intervenções.

Por isso, os docentes precisam desenvolver ações pedagógicas que atendam as especificidades dos alunos e as encaminhem aos respectivos profissionais, salientando que todos esses aspectos se refletem no trabalho dos educadores que, por vezes, precisam ter uma visão voltada para os acontecimentos que ocorrem dentro e fora do ambiente escolar, pois a escola é um espaço de socialização e interação social.

Todo docente carece estar atentos a realidade da turma e planejar ações interventivas de acordo a necessidade de cada aluno, e para isso o professor necessita constantemente realizar pesquisas para enfrentar as diversas situações encontradas na sala de aula, mas ele também precisa realizar avaliações tanto do planejamento quanto dos resultados alcançados pelos discentes.

$\mathrm{O}$ educador precisa assumir-se como um constante pesquisador, que precisa se inovar e construir novos conhecimentos indispensáveis para a sua formação, não deve se restringir a um tipo de conceito, $o$ qual precisa ser compreendido em diferentes ângulos para melhor entendimento. Uma boa formação deve partir do princípio de mudança profissional e pessoal, tendo como foco reconfigurar as práticas pedagógicas implantadas e aplicar projetos educativos, com o intuito de promover um ensino de qualidade.

Partindo deste princípio, compreende-se que formação continuada é um meio pelo qual permite aos profissionais da educação construir um novo olhar em relação a formação dos educadores e entender o ofício do magistério, o status profissional que contribui no seu desenvolvimento como formador de sujeitos críticos, os elementos identitários para a elaboração do seu perfil pessoal e as ações pedagógicas para tornar o ensino.

Deste modo, Carbonneau (2006) aponta que essa formação continuada é concebida como um caminho dos docentes para ampliarem seu campo de atuação, desenvolver suas competências, construir novos conhecimentos, adquirir informações, inovar suas práticas pedagógicas, interagir com outras pessoas, ampliando seus saberes e promovendo um aperfeiçoamento tanto profissional quanto pessoal mais eficaz dentro do ambiente escolar, de acordo a demanda correspondente ao tempo vivenciado.

Em consonância, Gatti assegura que ao:

[...] utilizar mais e melhor o conhecimento e a reflexão sobre as condições de trabalho dos professores, suas motivações, dificuldades, crises e mobilizações possíveis, considerando que esse conhecimento pode sustentar boas políticas de formação e de ação e práticas de gestão (GATTI, 2012, p.439).

Nesse posicionamento, é notório perceber que as pesquisas realizadas no campo da formação de professores, principalmente no território brasileiro, permitem uma autor-reflexão sobre a carreira profissional, um olhar direcionado aos desafios presentes no meio social e educacional, a busca por movimentos políticos para ajudar na oferta de investimentos mais eficazes no desenvolvimento de uma organização escolar participativa e democrática. Espera-se oferecer mudanças significativas na área de formação dos educadores que permita a construção de novo saber necessário.

A pesquisa apresentada apontou que o primeiro passo a ser dado para se ter mudanças significativas no campo educacional é realizar análises sobre as funções das instituições escolares, partindo do reconhecimento das políticas públicas que garantem formação docente. 
A metodologia deste estudo está ancorada na pesquisa qualitativa do tipo explicativa, tendo como instrumento de coleta das informações a entrevista semiestruturada com três professoras egressas do Curso de Pedagogia da Universidade do Estado da Bahia Campus XI Serrinha. Acatando as considerações de Santos et al (2018, p.19) “ A pesquisa qualitativa é [...] compreendida como um caminho metodológico que objetiva abordar, interpretar e compreender os fenômenos de forma contextual, relacional e complexa [...] a partir de compreensões e interpretações oriundas de vários campos e perspectivas".

As categorias explicitadas a seguir tiveram como princípio as falas das professoras, por meio de entrevistas semiestruturada, questão de pesquisa e o referencial teórico. Apresentam-se, neste artigo, quatro categorias: Formação docente e demandas da educação básica; Sentimentos sobre formação e a atuação na prática; Relação teoria e prática e Lacunas entre formação e atuação.

Na categoria Formação docente e demandas da educação básica emergiram as seguintes falas:

\begin{abstract}
Acredito muito na contribuição da formação de professores que trazem consigo uma rica experiência. [...] não há, na prática do trabalho, uma clareza dos objetivos mais específicos a serem atingidos. Isto se deve ao fato de que as diversas interações entre alunos e professores, posturas e condutas exigidas pela escola possuem natureza muito complexa, diluindo os objetivos primeiros da escola ao contorno de um problema particular, como exemplo, a indisciplina ou a execução de serviços meramente burocráticos [...] (PROFESSORA A, 2017).

[...] A formação na universidade tem contribuído para o meu crescimento profissional, intelectual e pessoal, uma vez graduada na área que você deseja atuar, tudo se torna melhor e mais fácil de compreender, a visão de mundo torna-se outra, passei a enxergar o ensino e aprendizagem de forma mais dinâmica e diversificada. [...] $\mathrm{O}$ que ficou das demandas [...] foram os conhecimentos teóricos, estudei muita teoria, dessas teorias que foram abordadas algumas delas se mantém presentes na minha atuação docente na educação básica, me respaldo nelas para desenvolver meu trabalho com mais qualidade, bem como a competência de gerenciamento do próprio desenvolvimento profissional. (PROFESSORA B, 2017).

[...] é na universidade que a gente tem a base teórica e assim a gente busca fazer essa base teórica com a nossa prática [...] a universidade [...] é o ponto chave pra gente ter esse embasamento [...] ela é fundamental pra gente ter uma atuação melhor em sala de aula. [...] Então assim continua tendo as demandas, o aluno que chega na escola sem acompanhamento de pais, o aluno que chega na escola sem ter embasamento da família, a escola que não tem o espaço adequado pra esse aluno, alunos com necessidades especiais, [...] a escola não são preparadas pra isso. (PROFESSORA C, 2017).
\end{abstract}

Com base nas falas das três professoras pode-se analisar que todas afirmam que a universidade contribuiu de forma significativa para a sua evolução como docente. Salientando, que a formação acadêmica é vista como um caminho de ampliação dos saberes, novas posturas, reconfigurações da prática educativa e construção de conhecimentos, essa etapa inicial é de suma importância para o desenvolvimento pessoal e profissional do graduado, sendo que oportuniza aos sujeitos desenvolverem um trabalho de qualidade.

Neste viés as pedagogas B e C explanam sobre diversas demandas presentes no campo da educação, seus enunciados relataram uma realidade vivenciada pelos educadores, em relação a complexidade do trabalho docente, visto como um desafio, pois neste espaço encontram-se diversas realidades sociais em que o professor precisa entendê-las para promover estratégias e possíveis soluções, é nesta conjuntura que se percebe os inúmeros problemas de aprendizagens encontrados pelos estudantes, a falta da participação do seio familiar no âmbito escolar, um fator que se mantém presente no século XXI, ressaltando que o elo entre família e escola é de extrema relevância para o progresso do aluno.

A fala da professora $\mathrm{C}$ apresenta uma realidade vivenciada nos espaços educacionais, em relação aos desafios que o professor lida constantemente, como as dificuldades de aprendizagens atreladas aos problemas psicológicos, a indisciplina e as realidades sociais distintas, são fatores que implicam diretamente no processo de ensino e aprendizagem. Para atender tais demandas os educadores precisam compreender as fases de desenvolvimento dos discentes, o processo cognitivo, as diversidades culturais e sociais, colocando em prática ações educativas que visem a evolução do ensino e aprendizagem e tudo isso só é possível através do estudo acadêmico.

Nóvoa (2009) aponta que o processo formativo se destacaria se houvesse mais estudos sobre "situações concretas", como o fracasso escolar, demandas nos projetos educativos, problemas sociais, pois assim haveria um ensino mais qualificado. Seria necessário o comprometimento e responsabilidade do docente no contexto educacional, buscando ser reflexivo diante do seu trabalho, revendo sua práxis e inovando a todo momento, essa ação de reflexão é um ponto chave para formação pessoal e profissional.

Corroborando com esse olhar Gatti (2011) afirma que a função do educador na contemporaneidade é vista como algo complicado, pois este profissional se depara com diversas realidades sociais, econômicas, culturais e intelectuais. A função docente, entretanto, não se restringe ao 
agrupamento de saberes construídos, nem ao domínio dos conteúdos escolares, mas a um conjunto de fatores que abrangem além da comunidade escolar as políticas públicas ou os programas escolares contemplados pela escola pública.

Neste sentido, a formação docente precisa ser vista como um elemento imprescindível na vida de cada educador, pois o contato com o espaço universitário é possível desenvolver suas potencialidades, aprimorar suas habilidades, ampliar saberes, ter novas posturas, apresentar visões críticas, modificar a prática educativa, dentre outras coisas. Vale ressaltar que o planejamento, a construção de conhecimentos, o respeito às diversidades, a aquisição de alternativas inovadoras na didática por meio de pesquisas, tudo isso, ajuda de maneira significante para o desenvolvimento da atuação profissional e consecutivamente no desempenho do aluno.

Neste viés, a segunda categoria apresenta sentimentos sobre formação e a atuação na prática, como cita as professoras A e C:

[...] eu gostaria de deixar registrado acerca teoria e prática na minha atuação docente [...] tanto a inicial quanto a contínua, precisa ser consistente, crítica e reflexiva, que seja capaz de fornecer os aportes teóricos e práticos para o desenvolvimento das capacidades intelectuais do professor, direcionando-o ao seu fazer pedagógico. (PROFESSORA A, 2017).

[...] Pra mim a formação universidade possibilitou dar esse caminho pra gente [...] o conhecimento teórico e a partir do conhecimento teórico você tem uma prática mais desenvolvida porque você tem o embasamento [...] quando a gente passa pela universidade você se sente mais preparado, mais reflexivo, conhece mais [...] (PROFESSORA C, 2017).

O sentimento frisado por essas pedagogas durante a formação docente explicita um vínculo com o princípio de segurança, sobretudo, na aplicação da práxis pedagógica, pois com base nos conhecimentos universitários cria-se uma nova visão referente a realidade na sala de aula.

Já a entrevistada B evidencia em sua fala:

O que gostaria de deixar frisado mesmo é a questão de primeiro entender o nosso Brasil, a nossa educação brasileira e buscar teóricos que estudem a nossa realidade [...] a gente vê muito que aconteceu em outros países e não aqui, estudos próprios do país, então é importante que a gente entenda primeiro o nosso país e faça a nossa educação, não se espelhar tanto só a educação de fora, fica muito distante da nossa realidade. (PROFESSORA B, 2017).

A professora B afirma que se a educação brasileira fosse analisada com base em teóricos nacionais, ou seja, com base nos problemas existentes no meio social, se a reflexão acontecesse a partir da real necessidade do setor educacional haveria mudanças significativas nesta área.

O contato com a formação possibilita o desenvolvimento desse olhar direcionado, a busca por novos saberes, a construção de uma conduta cidadã. $\mathrm{O}$ trabalho docente acontece com base nas vivências (experiências), segundo Larrosa (2002) as experiências acontecem por meio das ações pessoais interligada com os saberes, servindo como uma forma de orientar para que a aprendizagem seja significativa, sendo um elemento que permite ao sujeito reconhecer o próprio contexto, por meio de novas visões.

Tardif (2014) ao falar da "epistemologia da prática", conceitua - a como um agrupamento de conhecimentos que são aplicados no exercício docente, conhecimentos esses construídos no dia a dia através das experiências vivenciadas, de acordo ao contexto presente, com base nos comportamentos dos alunos, da organização escolar, dos valores adquiridos, das finalidades traçadas, entre outros fatores, para assim ressignificar a teoria com a prática.

Dessa maneira, a experiência acontece a cada momento, quando há algo que toca os sujeitos, esse fator permite compreender o verdadeiro sentido dos acontecimentos e possibilita elaboração de um novo saber. Esta experiência está relacionada com as ações pessoais e profissionais que ocorrem durante o seu desenvolvimento. A experiência da existência acontece de forma concreta, é com ela que os indivíduos constroem uma bagagem de conhecimentos essenciais para sua formação como cidadão.

Neste contexto, a terceira categoria apresenta a relação da teoria com a prática, pois é através das experiências que acontece a relação entre a teoria e a prática, durante o trajeto da formação acadêmica os/as graduandos/as adquirem informações e conceitos que servirão como base para aplicar no exercício docente. É nesta linha de pensamento que as professoras afirmam:

Eu como docente da educação básica faço a interligação do campo teórico [...] com a prática, aproveitando o que o aluno já sabe. Na minha prática também tento contribuir com minhas aulas da melhor maneira possível para os meus alunos ter uma excelente formação e, nesse tocante a teoria adquirida na universidade me ajudou muito nesse campo, sabe. Mas, infelizmente essa conexão não soluciona todos os problemas não, por que aí é uma gama de situações que o sistema de ensino impede [...] (PROFESSORA A, 2017). 
[...] Vejo as teorias como forma de garantir conhecimentos, saberes, para subsidiar o professor a tomar decisões na sua prática pedagógica, uma vez que o professor, se apropria do conhecimento e enxerga como benefício os saberes teóricos, essa teoria faz interligação direta com a prática, a exemplo: quando se refere às compreensões de aprendizagem, quando toma-se a decisão de escolher as melhores formas de trabalhar em sala de aula, quando consegue vencer as dificuldades no ambiente escolar e entender com clareza as novas possibilidades de uma atuação com qualidade (PROFESSORA B, 2017)

[...] a prática ela é um pouco da nossa experiência do dia a dia, o cotidiano, mais, ela precisa muito desse conhecimento teórico. Eu não posso [...] trabalhar minhas experiências sem ter um embasamento. Então a interligação acontece no momento que eu tenho a experiência mais eu tenho o foco teórico. [...]. Então esse embasamento ele acontece o tempo todo, no momento que eu tô planejando, [...] num texto que eu tô trabalhando [...] eu tô buscando esse embasamento teórico pra melhorar a minha prática e vê onde é que eu posso melhorar, onde é que posso acrescentar e o que também que eu posso tirar [...] (PROFESSORA C, 2017).

Os enunciados expostos testemunham a importância dos fundamentos teóricos apreendido no período acadêmico, através do contato com os pensadores estudados os/as graduandos/as constroem novos olhares, passam a compreender a profissão de forma mais reflexiva, encontram alternativas para tentarem solucionar as demandas que impactam na sua atuação, essa relação com a teoria possibilita rever suas metodologias e estarem inovando constantemente.

É nesta perspectiva que Tardif (2014) enfatiza em relação a práxis educativa, a qual deve ser dotada de estudos teóricos, científicos e sociais para que haja uma educação qualificada. São esses conhecimentos que norteiam o trabalho pedagógico, possibilitando ao educador aperfeiçoar suas habilidades, reconfigurar suas ações, desenvolver sua criticidade, no entanto é na prática que o professor aplica os conhecimentos apreendidos e molda os saberes construídos ao longo da sua trajetória de vida.

A fala da pedagoga A afirma que a teoria é essencial, mas nem sempre se pode fazer uma ligação com prática, pois no dia a dia escolar os professores encontram problemas e realidades distintas que dificultam o exercício dos educadores, os quais precisam buscar outras estratégias pedagógicas, pois nem sempre a teoria dá conta da demanda presente.

Os fundamentos teóricos estudados durante o processo de formação acadêmica são compreendidos como uma forma de orientar o profissional a conduzir sua prática pedagógica com segurança, eficácia e qualidade. As teorias têm uma função relevante em conduzir o trabalho do educador, apresentando estudos educacionais que permitem ao professor buscar soluções para as demandas vivenciadas no cotidiano, inovar sua práxis, enriquecer suas ações educativas em prol do ensino e aprendizagem dos/das discentes.

É no exercício docente que o/a professor/a irá colocar em ação o que foi apreendido no período de formação as teorias estudadas, os projetos de pesquisas elaborados e os conhecimentos científicos, é desta forma que estes profissionais irão analisar quais teorias podem auxiliá-los na aplicação das suas ações educativas para tentar solucionar as demandas educacionais que existem.

O/a educador/a é pautado/a por saberes diversos, os mesmos são embasados em concepções científicas, as quais enriquecem suas ações educativas, o profissional docente desenvolve sua práxis através dos princípios educacionais, da filosofia elaborada com a equipe escolar, de acordo com as suas experiências pessoais e profissionais, suas potencialidades são aprimoradas conforme suas vivências do dia a dia, construção e a troca de novos conhecimentos.

Portanto, o centro de qualificação possibilita no desenvolvimento de uma formação eficaz, permite que os profissionais docentes façam a relação das teorias adquiridas no processo acadêmico para serem aplicadas no seu ambiente de trabalho, neste campo universitário as ações educativas necessitam estar centradas no ensino e aprendizagem, contribuindo na elaboração de uma postura crítica, tornando os universitários verdadeiros pesquisadores, sendo que deve englobar todas as áreas de conhecimentos presentes nas licenciaturas.

Segundo Freire (1996) a formação é um momento que possibilita aos profissionais desenvolverem sua criticidade sobre a prática, oportunizando na busca de alternativas eficazes para melhorar o ensino, pois o cenário educacional exige que o educador se autoavalie frequentemente.

Deste modo, o campo teórico e prático necessita estar articulado e para isso os profissionais da educação devem seguir certas recomendações: além de se embasar nas correntes teóricas estudadas na universidade, devem buscar outros estudos de acordo a temática que necessitar, fazer parte da construção e reconstrução do PPP, ter conhecimento do planejamento curricular, da organização do corpo escolar, dos recursos didáticos, entre outros fatores. O conjunto desses elementos é de grande relevância para conduzir ao educador no desenvolvimento das suas funções profissionais e assim qualificando o campo educacional.

Gatti (2011) enfatiza que o percurso formativo não deve centrar-se somente nas grades curriculares, mas compreender o papel da educação no processo de instrução dos indivíduos, reconhecendo que o educador tem uma função de suma importância no desenvolvimento de cada 
discente, sendo que precisa estimular o educando a aprimorar os saberes adquiridos e elaborar mecanismos para que o mesmo construa novas fontes de conhecimentos propondo um sujeito ativo, crítico e autônomo.

Conforme o que foi apresentado, a quarta categoria dá ênfase as lacunas entre formação e atuação apresentando a seguinte fala:

\begin{abstract}
As lacunas que eu sinto nessa formação e a mais gritante é de fato a política partidária que dificulta tanto o nosso sistema de ensino e portanto a nossa formação. Vejo que o grande desafio do educador é, pela formação permanente, buscar subsídios teórico-práticos, para o exercício da docência, para a compreensão de que o conteúdo a ser trabalhado é uma síntese da humanidade, e que ao ser considerado relevante, conduz o aluno a transitar por ele, provocando inquietações que o fazem avançar ainda mais. Outra lacuna que também vejo é a atribuição de sentido ao programa curricular, organizando, criticando, relacionando o objeto de conhecimento e a realidade (PROFESSORA A, 2017).
\end{abstract}

Diante do exposto, entende-se que a política partidária é uma lacuna frisada pela professora A, sendo que a mesma se mantém presente dentro da educação básica e na formação docente, considerada como um fator que dificulta na sua atuação. Além disso, apresenta uma crítica sobre a elaboração do programa curricular, alegando que nem sempre este atende a realidade dos educandos.

Em contrapartida as pedagogas B e C, expõem outras lacunas educacionais:

\begin{abstract}
[...] Sobre as lacunas da formação sinalizo a falta de organização curricular do curso oferecido, penso que o foco da formação de professores parta da competência de atuação profissional (competência referentes ao comprometimento com os valores estéticos, políticos e éticos inspiradores da sociedade democrática, ao domínio dos conteúdos a serem socializados, de seus significados em diferentes contextos e de sua articulação interdisciplinar, domínio do conhecimento pedagógico, conhecimento de processos de investigação que possibilitem o aperfeiçoamento da prática pedagógica, gerenciamento do próprio desenvolvimento profissional, compreensão do papel social da escola), (PROFESSORA B, 2017).

$\mathrm{Na}$ verdade, a nossa vida de educador ela nunca é completa a gente vive em constante formação [...] lacunas que a gente sente é muitas vezes também um pouco da formação [...]. Então assim, [...] você encontra alunos especiais, [...] muitas vezes não tem essa formação para você ta trabalhando [...]. Então as lacunas que eu acho são essas, você tem que dar conta de uma situação a qual você não tem formação específica pra a situação [...] (PROFESSORA C).
\end{abstract}

As entrevistadas discorrem sobre a forma como o PPP do curso é elaborado, salientando que a matriz curricular precisa ser construída com base em fundamentos teóricos, englobando questões filosóficas, políticas, culturais, econômicos entre outras, cujo objetivo é enriquecer a formação docente tornando-os aptos no campo de atuação. Observa-se, então, que a pedagoga $\mathrm{C}$ explana sobre as inúmeras situações dentro da educação básica, quando menciona a inclusão. Segundo ela, incluir sujeitos com dificuldades na aprendizagem, indivíduos com necessidades especiais é considerado desafiador para o profissional, pois, na maioria das vezes, não é capacitado ou falta recursos didáticos para atender as especificidades de cada estudante.

Desse modo Carbonneau expõe:

[...]. Em suma, o tipo de formação atualmente oferecido pela maior parte das universidades pode dificilmente pretender a excelência profissional, ao menos no que diz respeito ao lado pedagógico. Trata-se de uma formação muito curta, frequentemente abstrata e geralmente com a aparência salpicada da formação disciplinar (CARBONNEAU, 2006, p.125).

O autor traz um aspecto relevante sobre os cursos de formação, quando afirma que a capacitação não é suficiente para formar os acadêmicos, além disso é aplicada em curto período, desta forma os sujeitos devem buscar outras especializações, pois estes são seres incompletos, os quais precisam se atualizar constantemente para atender os problemas socioeducativos.

Contudo, a universidade oferece formação inicial, o primeiro passo a ser dado, é imprescindível que o/a professor/a seja inserido/a na formação continuada. Com efeito, é preciso que cada educador/a busque se atualizar por meio de pós-graduações, pois o campo da educação está em constante transformação, a cada período é desenvolvido nova proposta para atender o momento vivenciado. No entanto, é necessário criar alternativas em prol do setor educacional com intuito de solucionar os problemas que impactam os sistemas sociais, políticos, econômicos e culturais.

Sabe-se que o/a docente precisa-se inovar a cada momento para atender o que está sendo exigido e vivenciado no meio social. É nesta conjuntura que Tardif (2014) explana sobre as formações continuadas e as especializações, as quais são necessárias para que os professores possam aperfeiçoar suas ações, desenvolver suas potencialidades e ter contato com novas experiências. 
Em virtude disso, a formação universitária não deve ser compreendida somente como uma conquista do diploma, mas uma maneira de fazer a diferença na sociedade, promovendo a humanização, contribuindo para que se tornem indivíduos críticos, autônomos, investigativos e sonhadores. Deve cada docente sentir o desejo de ser pesquisador /a principalmente de temas educacionais porque as pesquisas contribuem significativamente para (re) pensar o fazer pedagógico.

\section{CONSIDERAÇÕES FINAIS}

Diante das considerações feitas, compreende-se que a formação docente é um elemento fundamental para o desenvolvimento dos profissionais da educação. Neste processo, são oferecidos subsídios teóricos para auxiliar no norteamento da práxis pedagógica e garantir uma educação com mais qualidade. Através da pesquisa apresentada, foi possível entender a relevância da formação acadêmica no desenvolvimento das pedagogas, a importância da articulação entre a teoria e a prática no processo do ensino e aprendizagem, salientando que nem sempre se consegue fazer essa ligação, pois nas salas de aulas são encontradas diversas realidades, por isso o/a docente precisa utilizar estratégias diferenciadas para atender as demandas presentes.

Com base nas entrevistas, é notório observar que a formação de professores é imprescindível para que se tenha sucesso escolar. As narrativas expostas frisam que o suporte teórico é essencial no campo da educação, mas, muitas vezes, não solucionam os problemas enfrentados, por isso o curso é uma etapa inicial, sendo que os/as pedagogos/as precisam ampliar seus saberes, construir uma postura crítica, avaliar e inovar a práxis e assim elaborar um espaço escolar qualificado.

$\mathrm{O}$ estudo buscou apontar reflexões de professoras egressas do curso de Pedagogia da Universidade do Estado da Bahia (UNEB), campus XI, com a finalidade de observar as demandas formativas presentes no campo da educação.

Ademais, através dessa pesquisa refletimos sobre novos olhares diante das demandas formativas de pedagogas atuantes na educação básica, com o intuito de problematizar novas questões.

\section{REFERÊNCIAS}

CARBONNEAU, Michel. Modelos de formação e profissionalização do ensino: análise crítica de tendências norte-americanas. In: Revista da FAEEBA: Educação e contemporaneidade. Salvador, v.15, n.26, jul. /dez, 2006. p. 115-131.

FREIRE, Paulo. Não há docência sem discência. In:___Pedagogia da autonomia: saberes necessários à prática educativa. São Paulo: Paz e Terra, 1996. P.21 - 45.

GATTI, Bernadete A. Formação de professores e profissionalização: contribuições dos estudos publicados na Rbep entre 1998 e 2011. Brasília: Estudos RBEP, v.93, maio/ago, 2012. p. 423-442.

GATTI, Bernardete Angelina. Políticas docentes no Brasil: um estado da arte. Brasília: UNESCO, 2011. BONDÍA, Jorge Larrosa. Notas sobre a experiência e o saber de experiência. Espanha, jan/fev/mar/abr, 2002, p.20-28.

NÓVOA, Antônio. Para uma formação de professores construída dentro da profissão. In:____Professores Imagens do futuro presente. Lisboa: Educa, 2009.

SANTOS, Ana Kátia Alves dos. Pesquisa de natureza qualitativa e o estudo de caso: concepção e tipo. In: SANTOS, Ana Kátia Alves dos et al(org.).Práticas de pesquisa qualitativa: o estudo de caso na formação docente do Mestrado Profissional em Educação da FACED/UFBA.Curitiba:CRV,2018.p.19-30. TARDIF, Maurice. Saberes profissionais dos professores e conhecimentos universitários. In: Saberes Docentes e Formação Profissional. 17. ed. Petrópolis, RJ: Vozes, 2014.

TARDIF, Maurice. Elementos para uma teoria da prática educativa. In: Saberes Docentes e Formação Profissional. 17. Ed. Petrópolis, RG: Vozes, 2014. 


\section{Informações sobre os autores:}

KOJ: Graduada do Curso de Licenciatura em Pedagogia da Universidade do Estado da Bahia - UNEBCampus XI - Serrinha - BA. Bolsista de Iniciação Científica, pela Fundação de Amparo à Pesquisa do Estado da Bahia (FAPESB). Membro do Grupo de Pesquisa Epods.

IBA: Pós-Doutora em Educação e Contemporaneidade pelo PPGEduC/INEB. Doutora em Família na Sociedade Contemporânea pelo Programa de Pós-graduação da Universidade Católica do Salvador UCSAL. Professora Adjunta da Universidade do Estado da Bahia Campus XI. Professora e Vice Coordenadora do Mestrado Profissional em Intervenção Educativa e Social (MPIES). Líder do grupo de pesquisa Educação, Políticas Públicas e Desenvolvimento Social (EPODS) - UNEB/CAMPUS XI

CCV: Doutor em Letras pela Pontifícia Universidade Católica do Rio Grande do Sul (PUCRS), Mestre em Letras pela Universidade Federal da Bahia (UFBA), Coordenador Geral do Curso de Pedagogia PARFOR/UNEB. Professor do Mestrado Profissional em Intervenção Educativa e Social (MPIES) e pesquisador do EPODS.

Contribuição dos autores: KOK; IBA; CCV: conceitualização, captação de recursos, supervisão, redação. 